\title{
ASPECTS OF HARMONISATION OF INDIVIDUAL MONITORING FOR EXTERNAL RADIATION IN EUROPE: CONCLUSIONS OF A EURADOS ACTION
}

\author{
V. Kamenopoulou ${ }^{1, *}$, J.W.E. van Dijk ${ }^{2}$, P. Ambrosi ${ }^{3}$, T. Bolognese-Milsztajn ${ }^{4}$, C.M. Castellani ${ }^{5}$, \\ L. Currivan ${ }^{6}$, R. Falk ${ }^{7}$, E. Fantuzzi ${ }^{8}$, M. Figel ${ }^{9}$, J.Garcia Alves ${ }^{10}$, M. Ginjaume ${ }^{11}$, H. Janzekovic ${ }^{12}$, \\ D. Kluszczynski ${ }^{13}$, M.A. Lopez ${ }^{14}$, M. Luszik-Bhadra ${ }^{15}$, P. Olko ${ }^{16}$, H. Roed ${ }^{17}$, H. Stadtmann ${ }^{18}$, \\ F. Vanhavere ${ }^{19}$, E. Vartiainen ${ }^{20}$, W. Wahl ${ }^{21}$, A. Weeks ${ }^{22}$ and C. Wernli ${ }^{23}$ \\ ${ }^{1}$ GAEC, Greek Atomic Energy Commission, P.O. Box 60092, 15310 Aghia Paraskevi, Greece \\ ${ }^{2}$ NRG Radiation and Environment, Utrechtseweg 310, Postbus 9034, 6800 AS Arnhem, The \\ Netherlands \\ ${ }^{3}$ PTB, Physikalisch-Technische Bundesanstalt, P.O. Box 3345, D-38116 Braunschweig, Germany \\ ${ }^{4}$ IRSN, Institut de Radioprotection et de Surete Nucleaire, Fontenay-aux-Roses F-92265, France \\ ${ }^{5}$ ENEA-IRP, 40136 Bologna, Italy \\ ${ }^{6}$ RPII, Dublin 14, Ireland \\ ${ }^{7}$ SSI, Stockholm, 17116 Sweden \\ ${ }^{8}$ ENEA, Radiation Protection Institute, via dei Colli 16-40136 Bologna, Italy \\ ${ }^{9}$ GSF, National Research Center for Environment and Health, Institut for Radiation Protection, \\ 85764 Neuherberg, Germany \\ ${ }^{10}$ Instituto Tecnologico e Nuclear, Departamento de Proteccao Radiologica e Seguranca Nuclear, \\ Estrada Nacional 10, 2686-953 Sacavem, Portugal \\ ${ }^{11}$ Institute of Energy Technology, Technical University of Catalonia, Barcelona 08028, Spain \\ ${ }^{12}$ Slovenian Nuclear Safety Administration, Zelezna cesta 16, P.O. Box 5759-1-001, Ljubljana, Slovenia \\ ${ }^{13}$ NIOM, 8 Teresny street, P.O. Box 1998, LODZ, 90-950 Poland \\ ${ }^{14}$ CIEMAT-Dosimetry Unit, Avda. Complutense 22, 28040 Madrid, Spain \\ ${ }^{15}$ PTB, Physikalisch-Technische Bundesanstalt, Bundesallee 100, 38116 Braunschweig, Germany \\ ${ }^{16}$ Institute of Nuclear Physics, Radzikowskiego 152, Kraków 31 342, Poland \\ ${ }^{17}$ National Institute of Radiation Hygiene, Copenhagen, Denmark \\ ${ }^{18}$ ARC Seibersdorf Research GmbH, Siebersdorf 2440, Austria \\ ${ }^{19}$ Studiecentrum voor Kernenergie-Centre d'etude de l'energie nucleaire, Mol 2400, Belgium \\ ${ }^{20}$ STUK, Radiation and Nuclear Safety Authority, P.O. Box 14, Helsinki 00881, Finland \\ ${ }^{21} \mathrm{GSF}$, Forschungszentrum für Umwelt und Gesundheit, GmbH, Institut für Strahlenschulz, \\ Ingolstaedter Landstrasse 1, Neuherberg 85764, Germany \\ ${ }^{22}$ Magnox Electric plc, Berkeley Centre, Berkeley, Gloucestershire GL13 9PB, UK \\ ${ }^{23}$ Paul Scherrer Institute, CH-5232 Villigen PSI, Switzerland
}

Following the publication of the EU Council Directive 96/29, EURADOS coordinated two working groups (WGs) for promoting the process of harmonisation on individual monitoring of occupationally exposed persons in Europe. An overview of the major findings of the second WG is presented. Information on the technical and quality standards and on the accreditation and approval procedures has been compiled. The catalogue of dosimetric services has been updated and extended. An overview of national regulations and standards for protection from radon and other natural sources in workplaces has been made, attempting to combine the results from individual monitoring for external, internal and workplace monitoring. A first status description of the active personal dosemeters, including legislative and technical information, and their implementation has been made. The importance of practical factors on the uncertainty in the dose measurement has been estimated. Even if a big progress has been made towards harmonisation, there is still work to be done.

\section{INTRODUCTION}

The publication of the European Council Directive 96/29 EURATOM ${ }^{(1)}$ 'Laying down basic safety standards for the protection of the health of workers

*Corresponding author: vkamenop@gaec.gr and the general public against dangers arising from ionising radiation', raised the important issue of the free movement of workers occupationally exposed to ionising radiation. The concern about the coordination and approval procedures of dosimetry laboratories appeared as a natural consequence. Therefore, the European Radiation Dosimetry Group (EURADOS) undertook the challenging 
endeavour of investigating the degree of 'Harmonisation of Individual Monitoring in Europe'. In 1996 EURADOS set up a working group (WG) in order to investigate this level of harmonisation of the dosimetric requirements and procedures for individual monitoring (IM) in European Union (EU) Member States (MS). Taking into consideration the reported results and conclusions ${ }^{(2,3)}$ of the WG, EURADOS decided to continue the action by establishing a second WG in 2001 aiming at further harmonisation of IM in the EU MS and the candidate countries.

Apart from the $30 \mathrm{WG}$ members, around 200 colleagues from all over Europe contributed to the work. A network of some 200 laboratories in 28 countries working together for harmonisation has been established.

The work was accomplished by sending and evaluating questionnaires to individual monitoring services (IMS) in MS of EU, including the new MS of EU and Switzerland, Bulgaria, Romania, Serbia and Montenegro, and Ukraine.

The results of the WG activities were published ${ }^{(4)}$ and presented in the Workshop on Individual Monitoring in Vienna, 11-15 April 2005 (The proceedings will be published in Radiat. Prot. Dosim.). This paper gives an overview of the major findings of this study focusing on the aspects of harmonisation of individual monitoring for external exposure.

\section{SUMMARY OF THE EURADOS HARMONISATION STUDY}

The WG was chaired by J. van Dijk and its activities were divided into four subgroups, coordinated by E. Fantuzzi, M. A. Lopez-Ponte, T. BologneseMilsztajn and H. Stadtmann. All the activities were based on the principle that the term harmonisation does not mean that the services have to follow exactly the same procedures but that they aim at the same requirements and that their results should be comparable.

In the following, a summary of the major findings and conclusions of each of these subgroups is presented.

\section{Implementation of standards for $\mathbf{I M}^{(4,5)}$}

Although one of the issues addressed in the EC Directive $^{(1)}$ is that monitoring of the exposure should in general be done by approved IMSs, the directive gives no criteria for the approval of these services. There is, however, a consensus among professionals that approved IMSs should perform their services in agreement with the relevant international standards and recommendations.

Since the IMSs usually have a different legislation and regulation establishment within each country, a general framework of an IMS together with its connection with other bodies has been presented.

A compilation of the information on the use of standards relevant for IM practices, ranging from the calibration of dosemeters to the QA procedures to be applied to the overall dose evaluation process has been performed.

After clarifying the terms standards, documents of relevance and legislation, catalogues of existing standards [International Organisation for Standardisation (ISO), International Electrotechnical Commission (IEC), International Atomic Energy Agency (IAEA), national] and documents of relevance such as international recommendations and technical reports [International Commission on Radiological Protection (ICRP), International Commission of Radiation Units and Measurements (ICRU), IAEA, European Commission (EC), national] were compiled.

An update of the approval and accreditation procedures followed by the IMSs in European countries has been performed together with the clarification of the European situation for standardisation/accreditation/approval bodies and the knowledge of standards development in each country.

The role of European cooperation for accreditation and of European Collaboration in Measurement Standards (EUROMET) has been addressed under the common statement that the acceptance of dose results between countries would be facilitated if the IMSs and calibration laboratories obtain accreditation from bodies which have entered into mutual recognition agreements with similar bodies in other countries using the same international standard.

Some other points of interest that were observed are as follows:

- Implementation of standards can foster harmonisation in IM.

- ISO/IEC 17025 gives the best guidance for the QA in IM.

- Harmonisation of terminology is needed in standards. This in particular applies to the quantification of uncertainties in relation to requirements.

- The accreditation bodies in Europe operate within mutual agreements.

- In some countries accreditation is the decisive requirement for approval.

Finally, in order to facilitate the IMSs to clarify the existing situation, a summary of the management aspects and technical requirements, typical for the quality management system of an IMS has been presented.

The major conclusion that identifies the need for further action is the fact that one way towards 


\section{HARMONISATION OF INDIVIDUAL MONITORING}

harmonisation in IM would be to pursue common performance criteria to test dosimetric systems for approval. This could be completed by basing the performance criteria on a single approach to uncertainties in measurements and particularly on the overall uncertainty.

\section{Integration of monitoring for external and internal exposure into one individual dose estimate ${ }^{(4)}$}

The aim of this subgroup was to investigate how the IM results from external and internal radiation together with workplace monitoring could be combined into a complete and consistent system of IM to cover needs for individuals and national dose registers. An important aspect to deal with is how the dosimetric methods can be integrated such that the numerical dose values can be added to result into the total effective dose of the worker.

The first objective of this WG was to provide an inventory of methods and services for assessing the doses due to external radiation and a catalogue of techniques and laboratories for assessing the committed effective doses due to internal contamination. A relevant study was also carried out in relation to national standards/reference levels for exposures to radon and to other natural sources at workplace; in this case, very useful information was provided by the competent regulatory authorities of European countries.

The first EURADOS WG on IM had collected information relevant on IMSs for external radiation within the 15 EU MS and Switzerland. This information was updated and completed by adding information on IM in the new EU MS: Czech Republic, Estonia, Hungary, Latvia, Lithuania, Poland, Slovakia and Slovenia as well as information obtained from Bulgaria, Croatia, Romania, Serbia and Montenegro and Ukraine.

Information was received from 90 laboratories, of which 32 new in the current study, in 28 European countries. This information updates the previously published catalogue ${ }^{(2)}$ and includes new developments and changes in regulations and procedures in external dosimetry.

The end product of this work was the generation of the EURADOS database of European Dosimetric Data containing general information about the national policy and the IMSs, the technical information relevant to the dosemeter characteristics and the dose calculation algorithms, the energy and angle dependence, the sources used for calibration purposes and the general performance characteristics of the systems.

The main observation is that there is a continued need for harmonisation efforts in Europe in view of the large number of IMSs using a great variety of dosemeters with different types of detectors. In this respect, further work is needed and should among others aim at the periodical organisation of European intercomparisons of personal dosemeters.

In addition to exposures to artificial sources, the protection of workers from the exposure to natural radiation was addressed in the European Directive ${ }^{(1)}$.

In order to study the current situation, information on the exposure to radon and radon decay products in workplaces, as well as the exposure to NORMs (all naturally occurring radioactive materials where human activities have increased the potential for exposure in comparison to the unaltered situation) was collected.

The work focused on the relevant EU legislation in force, international reports and recommendations published in this matter, and national standards and regulations. A survey has been performed in 24 countries, and the information collected was presented ${ }^{(4)}$, showing the reference levels of radon gas at workplaces $\left(\mathrm{Bq} \mathrm{m} \mathrm{m}^{-3}\right.$ or $\left.\mathrm{Bq} \mathrm{h} \mathrm{m} \mathrm{m}^{-3} \mathrm{y}^{-1}\right)$ by country and the reference levels for other natural sources $\left(\mathrm{mSv}\right.$ or $\left.\mathrm{mSv} \mathrm{y}^{-1}\right)$, considering different scenarios: mines, other underground places, industry workplaces, waterworks, offices and schools.

The main issues raised by this study were as follows:

- ICRP and EU recommend actions.

- Most countries have standards or reference levels in place, of which many reflect the expected exposure of the workers.

- The standards for schools and offices are country specific.

- The minimum dose to be recorded varies by a factor of 100 .

- The findings of the survey are incomplete, since not all countries have replied.

The existing situation is complex. There is a need for increased harmonisation among European countries, in particular in the areas of regulation and reference levels in the workplace, in order to obtain a complete and consistent system of individual monitoring.

\section{Active personal dosemeters $^{(4)}$}

In modern radiation protection practices, active personal dosemeters (APD) are becoming a necessary tool for implementing ALARA principles. Despite their success, APDs are relatively new for individual monitoring of workers. A first evaluation of the implementation and use of APDs for individual monitoring in Europe was performed, including regulatory issues.

A questionnaire on the status of the use of APDs was distributed among EURADOS members. Detailed catalogues were created containing information coming from both the users and the 


\section{KAMENOPOULOU ET AL.}

manufacturers. Each country provided information concerning the regulatory requirements, the type of dosemeter used for legal dose records, the standard requirements for the use of APDs as well as their calibration and performance testing. The information provided by the manufacturers formed a detailed catalogue containing technical characteristics and properties of APDs used in Europe.

The following observations were made:

- APDs are increasingly used and their developments are fast.

- APDs are mostly used in the nuclear power plants and less so in the medical sector.

- The comparisons have shown significant differences.

- The most critical parameters in their use are the response at low energy photon and beta radiations as well as their mechanical characteristics.

- APDs comply with the international standards.

- APDs can be as reliable as the passive dosemeters, if properly selected for dosimetric and mechanical characteristics.

- Currently APDs can be an economical option only for large users.

The main conclusion of this study is that further investigation and improvement is required, in particular for extremity and neutrons dosimetry.

Moreover, harmonisation of calibration and testing procedures for APDs, as well as performance tests of both passive dosemeters and APDs are necessary in order to find optimum conditions for the use of APDs. In view of this and the continued development of new devices, an extension and revision of the present study will be needed in the near future. The current study resulted in joint actions by the IAEA and EURADOS starting the organization of an intercomparison exercise for APDs.

\section{Reliability of dosimetric systems ${ }^{(4)}$}

Results of performance tests verifying the dosimetric properties of dosimetric systems are widely published. However, there is hardly any information in the open literature relating to the uncertainty in a dose measurement or in the annual dose, which is increased by failure of the evaluation or data management system, by the damage of the dosemeter itself or by the loss of a dosemeter. An attempt has been made to estimate the importance of the above mentioned conditions, by sending questionnaires to about 200 IMSs, 88 of which responded, representing all sizes and dosimetric techniques.

The analysis of the answers confirmed our impression that the sources of increased uncertainty in IMSs are the inappropriate use of the dosemeter, the damage or loss of the dosemeter during its use, the damage of the dosemeter during its processing, the faulty conditions in the evaluating equipment and the loss of data during data processing.

- Whereas most IMSs assess the uncertainty, only a few used standards on the expression of uncertainty in measurements (ISO-GUM).

- A minority of the IMSs report an uncertainty on a regular basis.

- The majority of the IMSs uses a standard-based QA system.

- The majority of the IMSs is directly traceable to a secondary standards dosimetry laboratory (SSDL).

- Almost all IMSs report the dose results in personal dose equivalent.

- Almost all IMSs assign the dose directly to the individual.

- Almost all IMSs issue printed reports.

- Lost dosemeters range from 0 to $20 \%$ (higher values with films).

- IMSs use different methods to report and assign doses for non-returned dosemeters.

In view of harmonisation of IM in Europe, the last point is of particular interest.

\section{CONCLUSIONS AND PERSPECTIVES}

The open market and in particular the need for a uniform level of protection of occupationally exposed workers in all EU Member States requires that individual monitoring is harmonised and complies with the relevant international standards to ensure adequate levels of quality.

The collecting and dissemination of information that resulted from the EURADOS action enable the European services to pursue this goal. This second work cycle of the EURADOS WG accomplished its endeavour successfully. The most important achievement is the establishment of a network of IMSs within Europe, having similar interests and concerns.

However, issues that are of primary importance and that need continued attention and evaluation have been identified and these are as follows:

- Revision of the "technical recommendations for monitoring individuals occupationally exposed to external radiation', EUR 14852.

- Definition of procedures and criteria for approval of IMSs, aiming at a desirable mutual recognition of results.

- Maintain and continuously update the database of IMSs (including legislative, administrative and technical information).

- Harmonisation in extremity dosimetry. 
- Organisation of intercomparison exercises and performance characteristics testing on a regular basis.

EURADOS WG aims to assist in the establishment of a consistent system of high quality for all aspects of IM for radiation protection throughout Europe.

\section{ACKNOWLEDGEMENTS}

EURADOS could manage the activities of this WG thanks to the financial support from the European Commission under the fifth framework programme (EURATOM) of the Directorate General for Research and Development (FIR1-CT-2000-20104). The WG wishes to thank all their colleagues in the European Countries that supported this study by distributing and answering the questionnaires.

\section{REFERENCES}

1. Commission of the European Communities. Council Directive 96/29 EURATOM of 13 May 1996 laying down basic safety standards for the protection of the health of workers and the general public against dangers arising from ionising radiation. Off. J. Eur. Commun. L159, 39 (1996).

2. Bartlett, D. T., Ambrosi, P., Bordy, J. M., van Dijk, J. W. E. Harmonisation and dosimetric quality assurance in individual monitoring for external radiation. Rad. Prot. Dosim., 89(Special Issue 1-2), (2000).

3. Bartlett, D. T., Bohm, J. and Hyvonen, H. Individual monitoring of external radiation. Proccedings of a European Workshop, Helsinki, Finland, September 2000. Radiat. Prot. Dosim., 96 (1-3) (2001).

4. van Dijk, J. W. E., Bolognese-Milstzttajn, T., Fantuzzi, E., Lopez Ponte, M. A. and Stadtmann, H. Harmonising of individual monitoring in Europe. Radiat. Prot. Dosim., 112(Special Issue 1), (2004). 